\title{
Synthesis of melazolide B, a degraded limonoid, from a natural terpene precursor
}

\author{
Yannan Liu, ${ }^{\dagger}$ Alexander W. Schuppe, ${ }^{\dagger}$ Yizhou Zhao, Jaehoo Lee, Timothy R. Newhouse* \\ Department of Chemistry, Yale University, 225 Prospect St., New Haven, \\ Connecticut 06520-8107, United States. \\ *E-mail: timothy.newhouse@yale.edu

 \\ $( \pm)-\alpha$-ionone \\ (-)-melazolide B
}




\title{
Synthesis of melazolide B, a degraded limonoid, from a natural terpene precursor
}

\author{
Yannan Liu ${ }^{\mathrm{a}, 1}$, Alexander W. Schuppe ${ }^{\mathrm{a}, 1}$, Yizhou Zhao ${ }^{\mathrm{a}}$, Jaehoo Lee ${ }^{\mathrm{a}}$, Timothy R. Newhouse ${ }^{\mathrm{a},{ }^{*}}$ \\ ${ }^{a}$ Department of Chemistry, Yale University, 225 Prospect Street, New Haven, Connecticut 06520-8107, United States
}

\section{ARTICLE INFO}

\section{Article history:}

Received

Received in revised form

Accepted

Available online

Keywords:

melazolide B

limonoid

total synthesis

natural product

terpenoid

\section{ABSTRACT}

Degraded limonoids are a subclass of limonoid natural products that derive from ring-intact or ring-rearranged limonoids. Establishment of robust synthetic routes to access them could provide valuable materials to identify the simplest active pharmacophore responsible for the observed biological activities of the parent molecules. This communication delineates the development of a divergent strategy to furnish melazolide B and several other related congeners from a common ketolactone intermediate, which was rapidly assembled from $\alpha$-ionone. A chemoselective carbonyl $\alpha, \beta$-dehydrogenation and a Wharton reduction were key strategic steps in this synthetic pathway.

\section{Introduction}

Limonoids are a large family of terpenoid natural products with more than a thousand members isolated to date..$^{1-3}$ These phytochemicals display a broad array of biological activities, ranging from anti-cancer, anti-inflammation, antifeedant, and neurological activities. ${ }^{1-3}$ Due to their diverse and intricate structures as well as interesting biological profiles, several synthetic campaigns have targeted this family of natural products. ${ }^{4-13}$ Over the past few years, our group has reported the total synthesis of several rearranged limonoids and pyridine-containing bislactone limonoid alkaloids, ${ }^{10-12}$ such as

Scheme 1. Selected limonoids and structurally related compounds

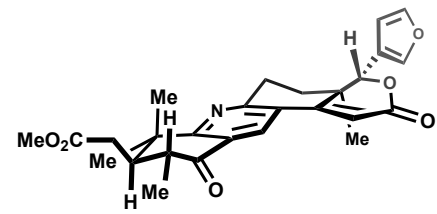

(+)-xylogranatopyridine B (1)

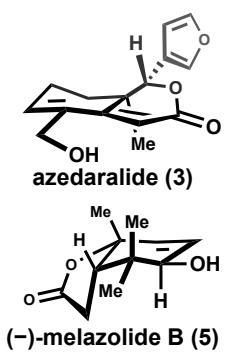

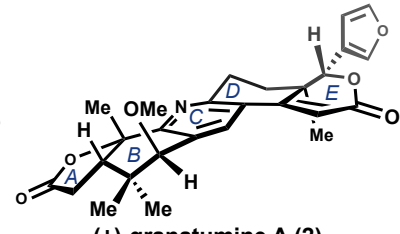

(+)-granatumine $A(2)$ [PTP1B inhibitory, IC ${ }_{50}=23 \mu \mathrm{M}$ ]

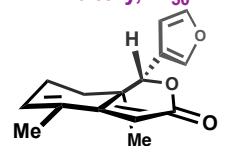

pyroangolensolide (4)

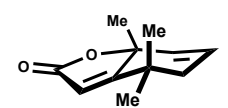

(-)-actinidiolide (6) xylogranatopyridine B (1) and PTP1B-inhibiting granatumine A (2). ${ }^{14}$ The establishment of these robust synthetic routes has enabled efficient access to them and their analogs for SAR studies. ${ }^{15}$ These investigations piqued our interest in identifying the active pharmacophore for the observed PTP1B inhibition.

Degraded limonoids, such as azedaralide (3), pyroangolensolide (4) and (-

\section{Scheme 2. Proposed biosynthesis of (-)-melazolide B}
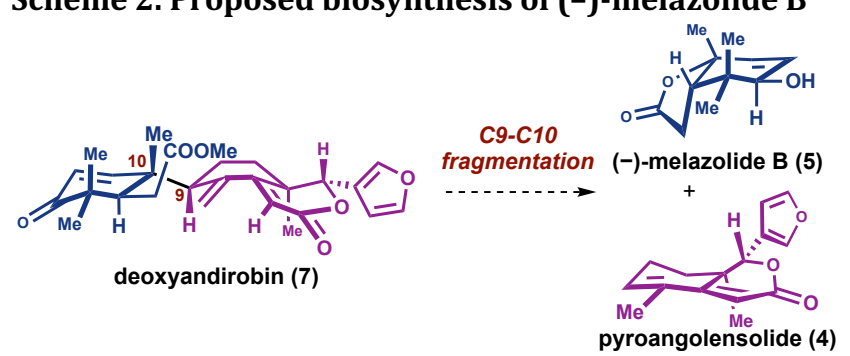

)-melazolide B (5), are a subclass of limonoid natural products arising from ring-intact or ring-rearranged limonoids. ${ }^{16}$ Although highly speculative at this juncture, Guerriero and co-workers hypothesized, based on the co-isolation of pyroangolensolide (4) and melazolide B (5), that they may derive from an uncertain common tetranotriterpenoid precursor such as deoxyandirobin (7) (Scheme 2). ${ }^{16}$ Fragmentation along the $\mathrm{C} 9-\mathrm{C} 10$ bond would yield fragments resembling degraded limonoid natural products (Scheme 2). ${ }^{16}$ Mechanistic proposals have previously been suggested but have not been substantiated. ${ }^{17,18}$

\footnotetext{
1 These authors contributed equally.

* Corresponding author. Department of Chemistry, Yale University, 225 Prospect Street, New Haven, Connecticut 06520-8107, United States.

Email address: timothy.newhouse@yale.edu
} 
Our established approach provided a synthetic pathway to access compounds related to the DE-ring fragments, such as azedaralide (3) and pyroangolensolide (4). ${ }^{12}$ Herein we disclose the development of synthetic routes to access compounds related to the AB-ring fragments, including (-)melazolide $B(5)$ and actinidiolide (6).

\section{Scheme 3. Synthesis of C3-epi-melazolide $\mathrm{B}^{a}$}<smiles>CC(=O)/C=C/[C@H]1C(C)=CCCC1(C)C</smiles>

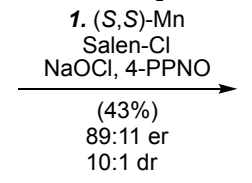<smiles>CC(=O)/C=C/[C@@H]1C(C)(C)CC[C@@H]2O[C@]21C</smiles>

( \pm )- $\alpha$-ionone (8)
9 2. $\left[\begin{array}{c}\mathrm{Rh}(\mathrm{COD})(\mathrm{OH})]_{2} \\ \mathrm{PhMe} \mathrm{SiH}^{2}\end{array}\right.$
$(89 \%)$

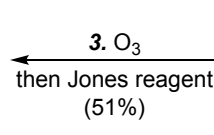<smiles>C/C(=C/C[C@H]1C(C)(C)CC[C@@H]2O[C@]21C)[GeH2]O</smiles>
4. KHMDS, PhNTf (84\%)
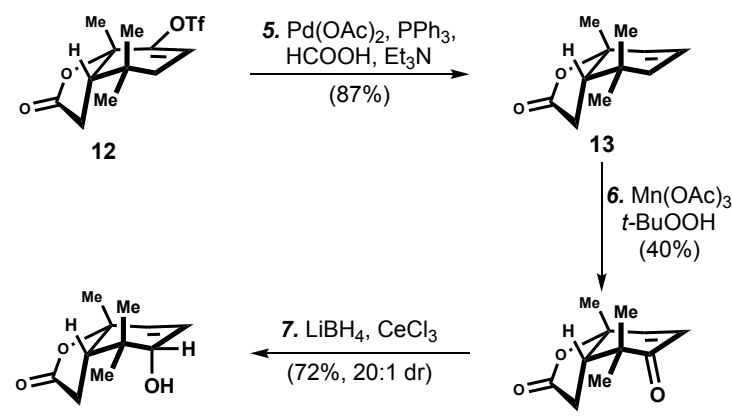

14

C3-epi-melazolide B (15)

B.
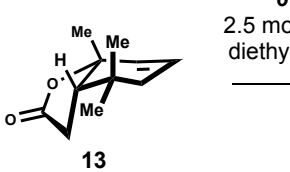

6'. Zn(TMP)

$5 \mathrm{~mol} \%[\mathrm{Pd}(\mathrm{allyl}) \mathrm{Cl}]_{2}$ diethyl allyl phosphate
$\mathrm{PhMe}$

(85\%)

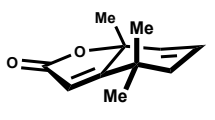

(-)-actinidiolide (6)
aReagents and conditions: (1) 5 mol \% (S,S)-(+)-N, N'-Bis(3,5-di-tertbutylsalicylidene)-1,2-cyclohexanediaminomanganese(III) chloride, 4phenylpyridine- $\mathrm{N}$-oxide ( $5 \mathrm{~mol} \%$ ), aq. $\mathrm{NaOCl}\left(1\right.$ equiv), $\mathrm{CH}_{2} \mathrm{Cl}_{2}, 0$ to $23^{\circ} \mathrm{C}$, 43\%, 89:11 er, 10:1 dr; (2) $1 \mathrm{~mol} \%$ [Rh(COD)(OH) $]_{2}, \mathrm{PhMe}_{2} \mathrm{SiH}$ (1.3 equiv), THF, 23 to $60{ }^{\circ} \mathrm{C}, 2 \mathrm{~h}, 89 \%$; (3) $\mathrm{O}_{3}$, acetone, $-78{ }^{\circ} \mathrm{C} 0.5 \mathrm{~h}$, then Jones reagent ( 2.0 equiv), 0 to $23^{\circ} \mathrm{C}, 2 \mathrm{~h}, 51 \%$; (4) KHMDS (1.3 equiv), $\mathrm{PhNTf}_{2}$ (1.3 equiv), THF, -78 to $23{ }^{\circ} \mathrm{C}, 1 \mathrm{~h}, 84 \%$; (5) $5 \mathrm{~mol} \% \mathrm{Pd}(\mathrm{OAc})_{2}, 10 \mathrm{~mol} \%$ $\mathrm{Ph}_{3} \mathrm{P}$, formic acid (2.0 equiv), $\mathrm{Et}_{3} \mathrm{~N}$ (3.0 equiv), $\mathrm{DMF}, 60^{\circ} \mathrm{C}, 0.5 \mathrm{~h}, 87 \%$ (6) $\mathrm{Mn}(\mathrm{OAc})_{3}$ (0.7 equiv), TBHP (5.0 equiv), EtOAc, $70{ }^{\circ} \mathrm{C}, 3 \mathrm{~d}, 40 \%$; (7) $\mathrm{LiBH}_{4}$ (2.0 equiv), $\mathrm{CeCl}_{3}$ (2.0 equiv), THF/MeOH, $0{ }^{\circ} \mathrm{C}$ to rt, $1 \mathrm{~h}, 72 \%, 20: 1 \mathrm{dr}$; (6') $\mathrm{Zn}(\mathrm{TMP})_{2}$ (1.0 equiv), diethyl allyl phosphate (1.0 equiv), $2.5 \mathrm{~mol} \%$ $\left[\mathrm{Pd}(\text { allyl) } \mathrm{Cl}]_{2}, \mathrm{PhMe}, 120^{\circ} \mathrm{C}, 3 \mathrm{~h}, 85 \%\right.$.

\section{Results and discussion}

Our initial plan focused on a bidirectional search between the known degraded limonoids, such as $\mathbf{5}$ and $\mathbf{6}$, and our previously reported intermediate 11. The benefit of $\mathbf{1 1}$ as a starting material goal is that it already contains the key ring systems, quaternary center, and two stereocenters common to these degraded limonoids. ${ }^{19}$ A cyclohexyl ketone would need to be converted to an allylic alcohol wherein the hydroxyl group has formally undergone a reductive transposition. As an added benefit, the route to $\mathbf{1 1}$ was robust, and involved conversion of $\alpha$-ionone (8) by a three-step sequence involving a kinetic resolution via Jacobsen epoxidation, ${ }^{20}$ 1,4-hydrosilylation, and oxidative cleavage, as shown in scheme 3A. ${ }^{12}$ Treatment of ketone 11 with KHMDS and $\mathrm{N}$-phenyl-bis(trifluoromethanesulfonimide) resulted in the formation of an intermediate vinyl triflate (12) in $84 \%$ yield, which was then reduced to alkene 13 in $87 \%$ yield (Scheme $3 \mathrm{~A}$ ). Other reductants employed in this Pd-catalyzed reduction, including $\mathrm{Et}_{3} \mathrm{SiH}$ and $\mathrm{Bu}_{3} \mathrm{SnH}$, were less effective in this context.

Conversion of alkene $\mathbf{1 3}$ to an intermediate enone was achieved by allylic oxidation utilizing $\mathrm{Mn}(\mathrm{OAc})_{3}$ and $t$-BuOOH. Employing alternative allylic oxidation conditions to furnish $\mathbf{5}$ or $\mathbf{1 5}$ directly, such as $\mathrm{SeO}_{2}$ and $\mathrm{Cr}$-based oxidants, were unsuccessful. A diastereoselective Luche reduction of the enone intermediate (14) resulted exclusively in the formation of C3-epimelazolide B (15).

Although 13 was not a viable intermediate to melazolide $B(5)$, considering our laboratory's lactone $\alpha, \beta$-dehydrogenation, ${ }^{21}$ we reasoned that subjection of 13 to lactone $\alpha, \beta$-dehydrogenation conditions could give rise to (-)actinidiolide (6), an ionone-related compound that was proposed to be produced from kiwiionoside in nature. ${ }^{22}$ Indeed, dehydrogenation of the lactone functionality in $\mathbf{1 3}$ with our laboratory's allyl Pd-catalyzed dehydrogenation conditions revealed that the conditions originally developed for ketone dehydrogenation were most effective (the $\mathrm{Zn}(\mathrm{TMP})_{2}$ and diethyl allyl phosphate system) to produce actinidiolide (6), as shown in scheme $3 B .^{21}$ Employing the conditions previously developed by our laboratory for ester ${ }^{23}$ or amide $^{24}$ dehydrogenation resulted in lower conversion and diminished yield ( $23 \%$ and $47 \%$ yield respectively). These results suggest that the $\mathrm{Zn}(\mathrm{TMP})_{2}$ system may be more general for the dehydrogenation of other basic functionalities.

In order to obtain melazolide B (5), we undertook an alternative route through enone 17 (Scheme 4). Several ketone dehydrogenation conditions of 11 was first examined. A two-step sequence involving TMS enol ether formation and dehydrogenation was first attempted. Treatment of ketone 11 with KHMDS and TMSCI resulted in $\mathbf{1 6}$ in $36 \%$ yield (Scheme $4 \mathrm{~A}$ ). Although the original Saegusa-Ito oxidation conditions only led to full decomposition of the sily enol ether starting material (16), ${ }^{25}$ subjection of 16 to Tsuji's modified conditions smoothly delivered the enone product (17) in $91 \%$ yield (Scheme 4A). ${ }^{26}$

\section{Scheme 4. Optimization of ketone dehydrogenation ${ }^{a}$}
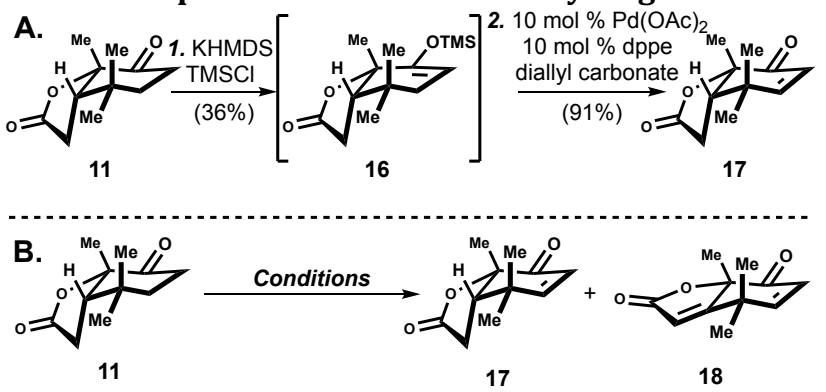

$$
\begin{aligned}
& \text { Entry Conditions } \quad \% \text { Yield }(19: 20)^{b} \\
& 1^{c} \quad 2.5 \mathrm{~mol} \%[\mathrm{Pd}(\text { allyl }) \mathrm{Cl}]_{2}, \mathrm{LiTMP}, \mathrm{ZnCl}_{2} \text {, allyl acetate } \quad 9: 0(30 \%) \\
& 2^{c} \quad 2.5 \mathrm{~mol} \%\left[\mathrm{Pd}(\text { allyl)Cl}]_{2}, \mathrm{LDA}, \mathrm{ZnCl}_{2} \text {, allyl acetate } \quad 1: 0(24 \%)\right. \\
& 3^{c} \quad 2.5 \mathrm{~mol} \%[\mathrm{Pd}(\mathrm{allyl}) \mathrm{Cl}]_{2}, \mathrm{Zn}(\mathrm{TMP})_{2}, \mathrm{ZnCl}_{2} \text {, diethyl allyl phosphate } 36: 39(95 \%) \\
& 420 \mathrm{~mol} \% \mathrm{NiBr}_{2} \cdot \text { glyme, } \mathrm{Zn}(\mathrm{TMP})_{2} \text {, diethyl allyl phosphate } \quad 0: 0(60 \%) \\
& 5 \quad \text { NaHMDS, Mukaiyama reagent } 25: 0(50 \%) \\
& 6 \text { LDA, Mukaiyama reagent } 6: 18(87 \%) \\
& 7 \quad \text { IBX, NMO, DMSO } 19: 0(99 \%) \\
& 85 \mathrm{~mol} \% \mathrm{Pd}(\mathrm{TFA})_{2}, \mathrm{DMSO}, \mathrm{AcOH}, \mathrm{O}_{2} \quad 64: 0(99 \%) \\
& 9^{d} \quad 5 \mathrm{~mol} \% \mathrm{Pd}(\mathrm{TFA})_{2} \text {, DMSO, } \mathrm{AcOH}, \mathrm{O}_{2} \quad 92: 0(99 \%)
\end{aligned}
$$

${ }^{a}$ Reagents and conditions: (1) KHMDS (1 equiv), TMSCl (1.5 equiv), THF, $78^{\circ} \mathrm{C}$ to rt, $2 \mathrm{~h} \mathrm{36 \% ;} \mathrm{(2)} 10 \mathrm{~mol} \% \mathrm{Pd}(\mathrm{OAc})_{2}, 10 \mathrm{~mol} \%$ dppe, diallyl carbonate (1.5 equiv), MeCN, $80{ }^{\circ} \mathrm{C}, 4 \mathrm{~h}, 91 \%$. ${ }^{b}$ Yield of the crude reaction mixture, using $0.05 \mathrm{mmol} 11$, was determined by ${ }^{1} \mathrm{H}$ NMR using 1,2-dibromomethane as an internal standard. Conversion of $\mathbf{1 1}$ in parenthesis. ${ }^{C}$ Reactions conducted on $0.2 \mathrm{mmol}$ scale. ${ }^{d}$ Conducted on a 3gram scale.

Several one-step dehydrogenation conditions were surveyed (Scheme 4B). Utilizing our laboratory's allyl-Pd-catalyzed dehydrogenation conditions ${ }^{21}$ (entries 1-3) resulted in overoxidation (18), however, the Ni-catalyzed dehydrogenation conditions only gave partially recovered starting material (entry 4). Employing either Mukaiyama's reagent ${ }^{27}$ (entries 5-6) or IBX (entry 7) resulted in minimal desired product. ${ }^{28}$ Subjection of $\mathbf{1 1}$ to Stahl's Pd- 
catalyzed aerobic dehydrogenation conditions afforded enone 17 with excellent selectivity (64:0, entry 8 ) and upon conducting on a 3-gram scale, excellent yield ( $92 \%$ yield, entry 9$).{ }^{29}$

With enone $\mathbf{1 7}$ in hand, we were ready to test the proposed synthesis of melazolide $\mathrm{B}(\mathbf{5})$ through Wharton reduction. ${ }^{30}$ Treatment of enone $\mathbf{1 7}$ with urea $\cdot \mathrm{H}_{2} \mathrm{O}_{2}$ effected a nucleophilic epoxidation to furnish epoxide 19 in $67 \%$ yield as a 1:1 mixture of diastereomers (Scheme 5). ${ }^{12}$ Reduction of the mixture of diastereomers of the $\alpha, \beta$-epoxy ketone (19 with Wharton's hydrazine protocol resulted in the formation of (-)-melazolide $B(5)$, via the intermediacy of hydrozone $\mathbf{2 0}$ (Scheme 5). ${ }^{30}$ Interestingly, during the reduction of the $\alpha, \beta$ epoxy ketone (19) with hydrazine only the desired diastereomer of the allylic alcohol 5 was observed, whereas the undesired diastereomer was degraded. It is unclear at this juncture what those decomposition pathway or pathways are, however the presence of an electrophilic lactone was possibly a liability. This six-step sequence marks the first reported synthesis of (-)-melazolide B.

\section{Conclusion}

In summary, we have documented efficient synthesis of C3-epi-melazolide $B$, melazolide $B$ and actinidiolide. Tapping into the natural terpene precursors by utilizing $\alpha$-ionone as a starting material accelerated the assembly of the core bicyclic structures and led to the first reported synthesis of (-)-melazolide

1. Q.-G. Tan; X.-D. Luo. Chemical reviews 111 (2011) 7437-7522.

2. a. D. Taylor. In Fortschritte der Chemie organischer Naturstoffe/Progress in the Chemistry of Organic Natural Products; Springer, 1984; pp. 1-102.

3. Y. Zhang; H. Xu. RSC advances 7 (2017) 35191-35220.

4. D. C. Behenna; E. J. Corey. J Am Chem Soc 130 (2008) 6720-6721.

5. J. M. Faber; W. A. Eger; C. M. Williams. J Org Chem 77 (2012) 89138921.

6. S. M. Fu; B. Liu. Organic Chemistry Frontiers 7 (2020) 1903-1947.

7. B. Heasley. European Journal of Organic Chemistry 2011 (2011) 1946.

8. C. Lv; X. Yan; Q. Tu; Y. Di; C. Yuan; X. Fang; Y. Ben-David; L. Xia; J. Gong; Y. Shen; Z. Yang; X. Hao. Angew Chem Int Ed Engl 55 (2016) 7539-7543.

9. D. M. Pinkerton; S. Chow; N. H. Eisa; K. Kainth; T. J. Vanden Berg; J. M. Burns; L. W. Guddat; G. P. Savage; A. Chadli; C. M. Williams. Chemistry 25 (2019) 1451-1455.

10. A. W. Schuppe; D. Huang; Y. Chen; T. R. Newhouse. J Am Chem Soc 140 (2018) 2062-2066.

11. A. W. Schuppe; T. R. Newhouse. J Am Chem Soc 139 (2017) 631-634.

12. A. W. Schuppe; Y. Zhao; Y. Liu; T. R. Newhouse. J Am Chem Soc 141 (2019) 9191-9196.

13. S. Yamashita; A. Naruko; Y. Nakazawa; L. Zhao; Y. Hayashi; M. Hirama. Angew Chem Int Ed Engl 54 (2015) 8538-8541.

$14 . \quad$ Z. F. Zhou; H. L. Liu; W. Zhang; T. Kurtan; A. Mandi; A. Benyei; J. Li; O. Taglialatela-Scafati; Y. W. Guo. Tetrahedron 70 (2014) 6444-6449.

15. T. Newhouse; A. Schuppe; Y. Liu; Y. Zhao; S. Ibarran; D. Huang; E. Wang; J. Lee; P. Loria. Chemrxiv (2021).

16. M. D'Ambrosio; A. Guerriero. Phytochemistry 60 (2002) 419-424.

17. A. Almeida; L. Dong; G. Appendino; S. Bak. Natural Product Reports 37 (2020) 1207-1228.

18. W.-S. Li; A. Mandi; J.-J. Liu; L. Shen; T. Kurtan; J. Wu. The Journal of Organic Chemistry 84 (2019) 2596-2606.

19. Z. G. Brill; M. L. Condakes; C. P. Ting; T. J. Maimone. Chemical reviews 117 (2017) 11753-11795.

20. E. N. Jacobsen; W. Zhang; A. R. Muci; J. R. Ecker; L. Deng. Journal of the American Chemical Society 113 (1991) 7063-7064.

21. Y. Chen; D. Huang; Y. Zhao; T. R. Newhouse. Angew Chem Int Ed Engl 56 (2017) 8258-8262.

22. T. Sakan; S. Isoe; S. B. Hyeon. Tetrahedron Letters 8 (1967) 16231627.

23. Y. Chen; J. P. Romaire; T. R. Newhouse. Journal of the American Chemical Society 137 (2015) 5875-5878.

24. Y. Chen; A. Turlik; T. R. Newhouse. Journal of the American Chemical Society 138 (2016) 1166-1169.
B. Among the reported synthesis of (-)-actinidiolide (6) including those from Jorgensen ( 7 steps), ${ }^{31}$ Eidman ( 7 steps) ${ }^{32}$, and Mori (10 steps), ${ }^{33-35}$ this six-step sequence represents an alternative and concise asymmetric synthesis of (-)actinidiolide (6). Our robust and scalable pathway will enable future investigations into the PTP1B inhibition of these and similar compounds.

\section{Acknowledgments}

Financial support for this work was provided by Yale University, Amgen, the Dreyfus Foundation, the Sloan Foundation, Bristol-Myers Squibb (Graduate Fellowship to A.W.S.), Roberts fellowship (to Y.L.), Dox fellowship (to Y.L.), National Science Foundation (GRFP to A.W.S), NSF CAREER (1653793), and the NIH (GM118614). We gratefully acknowledge the National Science Foundation for financial support in the establishment of the Yale University High Performance Computing (HPC) Center (CNS 08-21132).

\section{Supplementary Material}

Supplementary data to this article can be found online at [place holder].

\section{References and notes}

25. Y. Ito; T. Hirao; T. Saegusa. The Journal of Organic Chemistry 43 (1978) 1011-1013.

26. J. Tsuji; I. Minami; I. Shimizu. Tetrahedron letters 24 (1983) 56355638.

27. T. Mukaiyama; J.-i. Matsuo; H. Kitagawa. Chemistry letters 29 (2000) 1250-1251.

28. K. Nicolaou; Y.-L. Zhong; P. Baran. Journal of the american chemical society 122 (2000) 7596-7597.

29. T. Diao; S. S. Stahl. Journal of the American Chemical Society 133 (2011) 14566-14569.

30. P. Wharton; D. Bohlen. The Journal of Organic Chemistry 26 (1961) 3615-3616.

31. S. Yao; M. Johannsen; R. G. Hazell; K. A. Jørgensen. The Journal of organic chemistry 63 (1998) 118-121.

32. K. F. Eidman; B. S. MacDougall. The Journal of organic chemistry 71 (2006) 9513-9516.

33. K. Mori; V. Khlebnikov. Liebigs Annalen der Chemie 1993 (1993) 7782.

34. K. Mori; S. Aki. Acta Chemica Scandinavica 46 (1992) 625-629.

35. K. Mori; P. Puapoomchareon. Liebigs Annalen der Chemie 1991 (1991) 1053-1056.

TOC:

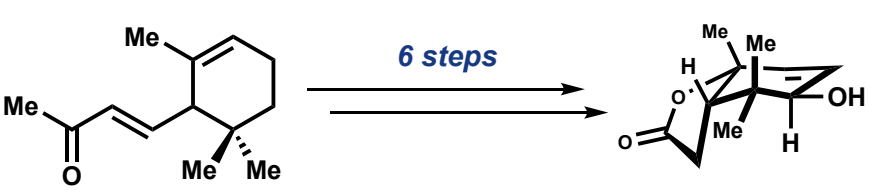

$( \pm)$ - $\alpha$-ionone

(-)-melazolide B 